\title{
Efficacy of living attenuated Salmonella typhimurium vaccine
}

\section{in poultry}

\author{
Hanan M. Ibrahim*, Zeinab M. Souror, N.A. Sherif, M. M. Lotfy, Elham A. El- \\ Ebiary, M. A. Makharita \\ Central Laboratory for Evaluation of Veterinary Biologics, Abbasia, Cairo, Egypt.
}

\begin{abstract}
The main goal of this study was to evaluate the protective efficacy of living attenuated Salmonella Typhimurium (S. Typhimurium) vaccine in poultry and to evaluate its use in control of salmonella infection in chickens. Oral vaccination of chickens within 36 hours after hatching and after 6 weeks from the first dose induced a strong humoral immune response as measured by ELISA. Challenge test was done with virulent strain of S. Typhimurium. Shedding of $S$. Typhimurium was detected during the first day, but after 14 days, salmonella could not be detected in the internal organs of vaccinated chickens compared with the non-vaccinated challenged chickens.
\end{abstract}

Salmonella is considered as one of the important causative agents which infect poultry farms specially that which apply the modern intensive system of rearing and management. Any contributions for elimination of salmonella in birds could have a major influence in reducing the populations of the organism under natural conditions (Bouzoubaa et al., 1989; Holt et al., 1996).

Many workers, allover the world, have been trying to control and eradicate salmonellosis in poultry by vaccination. Live attenuated salmonella vaccines may be hazardous because the residual virulence due to insufficient attenuation (Arnon et al., 1983).

The currently available against salmonellosis vaccines can be divided into three major classes: bacterins, attenuated and subunit vaccines. Protection induced by bacterins in poultry is generally mild; killed vaccine elicits good antibody responses but induce poor cell mediated immunity. Live attenuated vaccines have multiple advantages because of their ease of administration, ability to carry heterologous antigens and capacity to induce cellular and humoral immune responses (Ciacci-Woolwine et al., 1998).

Live attenuated vaccines activate the cell mediated immunity due to the specific cytokines response of dendritic cells during antigen presentation (Norimatsu et al., 2004). However,

\footnotetext{
* Corresponding author. Tel.: +202 3422505; Fax: +202 3449204

E-mail address: clevb@tedata.net.eg (Hanan M. Ibrahim)
}

the selection of construction of live vaccines requires the consideration of several issues. The vaccine must be sufficiently attenuated so as to be suitable for immune compromised individuals, while still remaining immunogenic. Also, the vaccine should be not spread and survive in the environment. So, the aim of the present work was to study the efficacy of living attenuated Salmonella typhimurium vaccine in chickens.

\section{Material and methods}

Vaccine. A live freeze dried vaccine (Avipro Salmonella CT, Lohman Animal Health Co.) containing an attenuated strain of $S$. typhimurium was used. One dose contains at least $1 \times 10^{8} \mathrm{CFU}$ live Salmonella typhimurium bacteria.

Bacterial strain. Local isolate of pathogenic strain of Salmonella Typhimurium was kindly obtained from Veterinary Serum and Vaccine Research Institute, Abbasia, Cairo. This strain was confirmed morphologically, biochemically and serologically.

Experimental animals.

Experimental chicks. A total of 200, one day old specific pathogen free (SPF) chicks were obtained from Koum Osheim Farm, Fayoum Governorate, Egypt. They were housed in isolators and kept under strict hygienic measures. Mice. A total of 250 Swiss white mice, weighing 10-20 g were used for passage and determination of $\mathrm{LD}_{50}$ of Salmonella strain.

Experimental design. The chicks were divided into two main groups, the first group (120 chicks) was given $1^{\text {st }}$ vaccine dose orally at 36 hours after hatching with the $1^{\text {st }}$ moment water intake, while the $2^{\text {nd }}$ dose of vaccine was given at 
Table (1): Fecal shedding and reisolation of S. Typhimurium from different organs of vaccinated and non-vaccinated chicken.

\begin{tabular}{|c|c|c|c|c|c|c|c|c|c|}
\hline \multirow[t]{2}{*}{ Groups } & \multirow[t]{2}{*}{$\begin{array}{l}\text { No. of } \\
\text { birds }\end{array}$} & \multicolumn{4}{|c|}{$\begin{array}{c}\text { Positive isolation from } \\
\text { cloaca } \\
\text { (Days Post Vaccination) }\end{array}$} & \multicolumn{2}{|c|}{$\begin{array}{l}\text { Positive isolation } \\
\text { from organs/day }\end{array}$} & \multirow{2}{*}{$\begin{array}{l}\text { Total No. of } \\
\text { +ve isolation } \\
\text { from organs }\end{array}$} & \multirow{2}{*}{$\begin{array}{c}\% \text { of } \\
\text { reisolation } \\
\text { from organs }\end{array}$} \\
\hline & & 3 & 7 & 14 & 21 & 7 days & 14 days & & \\
\hline Vaccinated & 120 & $20 / 20$ & $20 / 20$ & $15 / 20$ & $4 / 20$ & $5 / 20$ & $10 / 20$ & $15 / 40$ & $37.5 \%$ \\
\hline Control & 80 & $0 / 10$ & $0 / 10$ & $0 / 10$ & $0 / 10$ & $0 / 20$ & $0 / 20$ & $0 / 40$ & $0 \%$ \\
\hline
\end{tabular}

Table (2): ELISA mean absorbance values in sera of chickens vaccinated with live attenuated vaccine

\begin{tabular}{|c|c|c|c|c|c|c|c|c|c|c|c|c|c|}
\hline \multirow{3}{*}{ Groups } & \multirow{3}{*}{$\begin{array}{l}\text { Pre- } \\
\text { vacc. }\end{array}$} & \multicolumn{12}{|c|}{ Weeks Post Vaccination } \\
\hline & & \multicolumn{6}{|c|}{ First Dose } & \multicolumn{3}{|c|}{ Second Dose } & \multicolumn{3}{|c|}{ Challenge } \\
\hline & & 1 & 2 & 3 & 4 & 5 & 6 & 1 & 2 & 3 & 1 & 2 & 3 \\
\hline Vaccinated & 0.248 & 0.755 & 1.334 & 1.416 & 2.096 & 2.196 & 2.305 & 2.358 & 2.539 & 2.667 & 2.217 & 2.050 & 1.915 \\
\hline Control & 0.248 & 0.270 & 0.248 & 0.312 & 0.277 & 0.274 & 0.299 & 0.248 & 0.277 & 0.312 & 1.243 & 1.334 & 1.018 \\
\hline
\end{tabular}

Pre-vacc.: Pre-vaccination

Table (3): Blastogenic response of peripheral blood lymphocytes of chicken vaccinated with live attenuated vaccine using MTT assay

\begin{tabular}{|c|c|c|c|c|c|c|c|c|c|c|c|c|c|}
\hline \multirow{3}{*}{ Groups } & \multirow{3}{*}{$\begin{array}{l}\text { Pre- } \\
\text { vace. }\end{array}$} & \multicolumn{12}{|c|}{ Weeks Post Vaccination } \\
\hline & & \multicolumn{6}{|c|}{ First Dose } & \multicolumn{3}{|c|}{ Second Dose } & \multicolumn{3}{|c|}{ Challenge } \\
\hline & & 1 & 2 & 3 & 4 & 5 & 6 & 1 & 2 & 3 & 1 & 2 & 3 \\
\hline \multirow{3}{*}{ Vaccinated } & \multirow{3}{*}{0.064} & 1.09 & 1.43 & 1.52 & 1.39 & 1.23 & 1.09 & 1.36 & 1.73 & 1.64 & 1.58 & 1.51 & 1.43 \\
\hline & & \pm & \pm & \pm & \pm & \pm & \pm & \pm & \pm & \pm & \pm & \pm & \pm \\
\hline & & $0 . \overline{0} 4$ & $0 . \overline{0} 06$ & $0 . \overline{0} 18$ & $0 . \overline{0} 2$ & $0 . \overline{0} 09$ & $0 . \overline{15}$ & $0 . \overline{0} 3$ & $0 . \overline{0} 4$ & $0 . \overline{0} 3$ & $0 . \overline{0} 2$ & $0 . \overline{005}$ & $0 . \overline{006}$ \\
\hline \multirow{3}{*}{ Control } & \multirow{3}{*}{0.066} & 1.09 & 1.19 & 1.07 & 1.09 & 1.07 & 1.07 & 1.09 & 1.23 & 1.23 & 1.22 & 1.19 & 1.09 \\
\hline & & \pm & \pm & \pm & \pm & \pm & \pm & \pm & \pm & \pm & \pm & \pm & \pm \\
\hline & & $0 . \overline{0} 4$ & $0 . \overline{0} 4$ & $0 . \overline{0} 2$ & $0 . \overline{0} 4$ & $0 . \overline{0} 4$ & $0 . \overline{0} 4$ & $0 . \overline{0} 4$ & $0 . \overline{009}$ & $0 . \overline{0} 09$ & $0 . \overline{0} 03$ & $0 . \overline{0} 4$ & $0 . \overline{0} 4$ \\
\hline
\end{tabular}

Pre-vacc.: Pre-vaccination

6 weeks of age. The second group ( 80 chicks) was kept as non vaccinated controls.

Blood samples. Blood samples were collected weekly after $1^{\text {st }}$ dose, till the end of the experiment. The immune response was measured by determination of cell mediated immunity and ELISA.

Faecal swabs. Cloacal swabs were taken from vaccinated birds to detect shedding of salmonella.

Internal organ samples. Random organ samples (Heart, liver, spleen and caecum) from each group were collected by scarifying birds weekly to detect presence of salmonella in internal organs.

Challenge. All vaccinated and non- vaccinated groups were intramuscularly challenged by administration of the virulent $S$. typhimurium (Dose $7 \times 10^{8} \quad \mathrm{CFU} / 0.1 \mathrm{ml}$ ) according to (Adriaensen et al., 2007).

Cloacal swabs were taken at regular intervals till the end of experiment to observe shedding of $S$. typhimurium after 5 days of challenge. The birds of vaccinated and non-vaccinated groups were scarified and samples from liver, spleen and caecum were examined bacteriologically.
Separation of chicken peripheral blood lymphocyte. According to (Lucy, 1978).

Determination of viable lymphocytes. According to (Lucy, 1978).

Evaluation of humoral immune response. ELISA was carried out according to (Vollar et al., 1976). It was performed by using a commercial ELISA kit (Biochek Co., Holland). The serum dilution was 1:100. Optical density of samples was read at $405 \mathrm{~nm}$.

\section{Results and Discussion}

Studying of S.typhimurium shedding from the vaccinated chicken group post challenge with virulent strain revealed that the organism could only be isolated in the cloaca during the first 14 days after vaccination. The organism could only be isolated from cloacal swabs of the groups which received the vaccine.

Shedding of $S$. typhimurium was detected during the first 2 weeks but after 14 days no salmonella could be isolated from the organs of the chickens killed at the end of the trial, this also was obtained by (Desmidt et al., 1998).

Active immunization assay was detected using ELISA which expressed as the mean absorbance values. At the beginning of the 
experiment (one day old), anti-S. typhimurium antibodies were not produced by any of the birds. Two weeks after first vaccination, birds immunized with attenuated vaccine produced high amount (2.305) of antibodies and after second vaccination the amount of antibodies further increased (2.667). This was in parallel with the results of (Barrow, (1992; Barrow et al., 1992).

In evaluation of the cell mediated immune response for chickens vaccinated with live attenuated vaccine the results revealed that the maximum mean absorbance value (1.43) and (1.52) were noted at second and third week post vaccination and (1.73) and (1.64) at second and third week post boostering. The control nonvaccinated group showed steady level during all intervals except for slight increase to 1.23 reached post challenge. From the previous results, it could be concluded that living attenuated S.typhimurium vaccine can be useful in the control of $S$. typhimurium infection in chickens.

\section{References}

Adriaensen, C.; Henride Greve, Jean, Q.; Tian, Stephane De Craeye and EIne Gubbles (2007): A live Salmonella Enteritica serovar Enteritidis vaccine allows serological differentiation between vaccinated and infected animals. Infect. Immun., 2007.

Arnon, R.M.; Shapira and Jacob, C.O. (1983): Synthetic vaccines. J. Immu. Methods, 61: 261-273.

Barrow, P.A. (1992): ELISA and the serological analysis of salmonella infections in poultry. Epidem. Infect., 109 (3): 361-399.

Barrow, P.A.; Berchieri, A.J. and Al-Hajad, O. (1992): Serological response of chickens infected with Salmonella Gallinarum - Salmonella Pullorum detected by enzyme linked immunosorbent assay. Avian Dis., 36: 227-236.

Bouzoubaa, K.; Nagraja, K.V.; Kabbaj, F.Z.; Newman, J.A. and Pomeroy, B.S. (1989): Feasibility of using proteins from Salmonella Gallinarum, live vaccine for protection of fowl typhoid in chickens. Avian Dis., 33: 385391.

Ciacci-Woolwine, F.; Blomfield, I.C.; Richardson, S.H. and Mizel, S.B. (1998): Salmonella flagellin induces tumer necrosis factor alpha in a human promonocytic cell line. Infect. Immun., 66: 1127-1134.

Desmidt, M.; Ducatelle, R.; Mast, I.; Goddeeris, B.M.; Kaspers, B. And Haesebrouck, F. (1998): Role of humeral immune system in Salmonella Enteritidis for infection in chickens. Vet. Immunol. Immunopathol., 63: 355-367.

Holt, P.S.; Maeri, N.P. and Porter, R.E. (1996): Microbiological analysis of the early Salmonella Enteritidis. Vet. Bull., 66 (5): 2858.

Lucy, F. Lee (1978): Chicken lymphocyte stimulation by mitogens: A. Microassay with whole blood cultures. Avian Dis., 22 (2): 296 - 307.

Norimatsu, M.; Chance, V.; Daugan, G.; Haward, C.J. and Villarreal-Ramos, B. (2004): Live Salmonella Enterica serovar Typhimurium elicit dendritic cell responses that differ from those induced by killed $\mathrm{S}$. Typhimurium. Vet. Immun. Immunpathol., 98: 193-201.

Voller, A.; Bidwell, D.E. and Annbart, S. (1976): Enzyme immunoassay in diagnostic medicine, theory and practice. Bull. World. Hlth. Org., 53: 55-65.

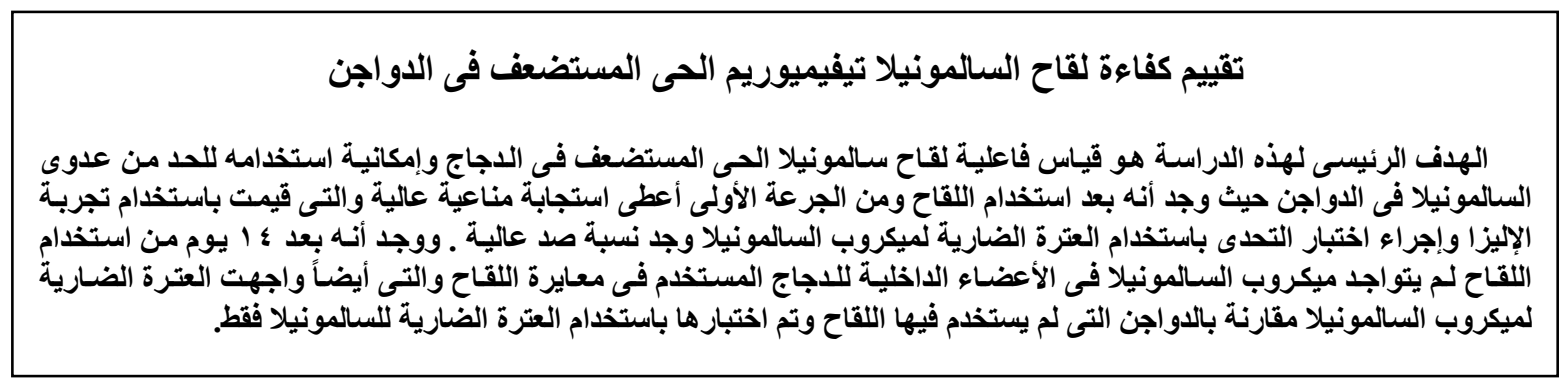

